Article

\title{
FDI, Institutional Quality, and Bribery: An Empirical Examination in China
}

\author{
Kum-Sik $\mathrm{Oh}^{1}$ and Yeon-Sik Ryu ${ }^{2, *}$ \\ 1 Division of Undeclared and Exploratory Majors, Pukyong National University, Busan 48513, Korea \\ 2 School of Business Management, Hongik University, Sejong 30016, Korea \\ * Correspondence: bluerys@mail.hongik.ac.kr
}

Received: 26 June 2019; Accepted: 23 July 2019; Published: 25 July 2019

\begin{abstract}
This study attempts to identify the key factors inhibiting the bribery practices of multinational enterprise (MNE) subsidiaries directed at local managers in China. During the experiment, this study employs an institutional theory, identifies primary determinants on the phenomenon, and compares the main components between old versus young subsidiaries. Data were collected through a questionnaire survey and both regression and spearman rank order correlation analyses were used as statistical techniques. Through the analyses, we found that a cognitive pillar is a crucial element contributing to the inhibition of bribery practices, the enhancement of institutional quality, and the promotion of sustainable development in the emerging economy. We expect that the results will provide useful implications for MNE managers planning to invest in China and for policy makers enacting institutional environments.
\end{abstract}

Keywords: foreign direct investment; institutional theory; bribery; emerging economy; sustainability in China

\section{Introduction}

As global competition continues to intensify, foreign direct investment (FDI) is increasingly becoming the crucial strategic option for multinational enterprises (MNEs) to win against other competitors. Therefore, the volume of FDI has increased dramatically in the past two decades $[1,2]$. In addition, FDI is often regarded as a prime mover, which positively contributes to various areas, particularly in emerging economies [3]. For instance, the inflow of FDI commonly helps host economies to develop institutional quality so that firms in those economies will be able to promote organizational renewal and strengthen sustainable competitive advantage in the long run [4].

To reiterate, based on the expected benefits of FDI, a common perception is that the attraction of FDI is its role as a shortcut leading to institutional evolution, which again results in a decrease in bribery by businesses, including MNEs. Although a number of studies have explored corruption (e.g., $[5,6])$ and bribery (e.g., [7,8]), to our best knowledge, no one has examined the issue by connecting institutional quality with MNE bribery, particularly in the international business domain. We believe that this topic can attract scholarly attention as bribery and informal payments are virtually illegal in all countries but remain prevalent in every corner of the world [9], though ironically this has not been cemented by prior literature [10].

To fill this research gap, the paper aims to identify which institutional pillar contributes to a decrease in MNE bribery in China, which is the largest emerging economy in the world. By doing this, we expect that we will, in turn, pinpoint any lacking institutional pillars that need to be complemented to strengthen sustainability in China. In particular, MNEs face multiple country institutional environments, each with its own set of regulatory, cognitive, and normative domains. The configuration and structure of these institutions, and their legitimacy requirements generally differ 
across national boundaries. Through a series of empirical analyses employing both regression and Spearman rank order correlation techniques, we uncovered that a cognitive pillar functions as a vehicle to inhibit bribery practices by MNE subsidiaries in China. We believe that our findings contribute to extending our understanding of the relationship between institutional quality and MNE bribery and provide useful implications for MNE managers wanting to operate abroad and host governments attracting FDI. In order to achieve the research objective, the point of departure (i.e., theoretical background and hypotheses development section) is a brief review of institutional theory, and then we develop the research model (i.e., hypotheses). The next section, the methodology, describes the data and measures employed. The subsequent section (i.e., results and discussions) presents the empirical findings and discusses the results. Finally, future research avenues are suggested and, as noted above, the paper concludes with implications for MNE managers and policy makers who intend to use FDI as a springboard to achieve economic takeoff and achieve the status of an advanced economy.

\section{Theoretical Background and Hypotheses Development}

A critical principle of institutional theory is that organizations are required to attain and sustain external legitimacy, defined as "a generalized perception or assumption that the actions of an entity are desirable, proper, or appropriate within some socially constructed system of norms, values, beliefs and definitions" [11]. In this vein, firms running their business under a similar environment have a propensity to choose analogous organizational practices and share isomorphic strategies with one another [12].

Such institutional factors often influence various domains and territories associated with MNE operations, and one example may include an MNEs' location decision and activity. For instance, Valentino and his colleagues [13] argue that a deterioration of a host country's institutional quality tends to increase the propensity to relocate the investment location. In contrast, an increase in the institutional distance between the host market and the home country of corporate headquarters does not force MNEs to relocate their subsidiaries to another country. However, Shukla and Cantwell [14] point out that although institutional distance does not play a strongly negative role in choosing an investment location, institutional affinity makes a location attractive to international firms. In a similar vein, Li et al. [15] shed light on the importance of institutional compatibility by saying that compatibility between firm practices and home-country institutional conditions can positively affect a firm's outward FDI activities because it will be easier for MNEs to secure legitimacy in that situation.

Meanwhile, as globalization has intensified, MNEs willing to do business in foreign countries and targeting various international markets increasingly need to conform to the institutional regulations and instructions imposed by each local environment with other rivals, because this isomorphism offers international firms (i.e., MNEs) legitimacy in their specific global markets. As commented above, while organizations sharing an identical business environment will often tend to exercise comparable strategies to obtain legitimacy, Hillman and Wan [16] propose that international firms operating businesses in foreign markets face certain costs that virtually all local firms do not. These costs are often referred to as a liability of foreignness, and their occurrence is closely related to institutional aspects residing in alien environments. In fact, MNEs and institutions are highly inter-related each other. According to his seminal work, Hymer [17] regards MNEs as the institution of capitalism per se. Meanwhile, institutions are the human-designed constraints that structure political, economic, and social interaction [18], and thus the host country commonly has its own unique institutional characteristics and pressures. Along with the normal constraints of economics, the choice set and a series of operation costs in local markets, and therefore the profitability and feasibility of engaging in economic activity are considerably determined by host country institutions. In addition, it is common wisdom that institutions gradually evolve while they link the past with the present and the future (see, [18]). From the perspective of the host country, it (i.e., host country) normally has less information with which to judge whether an MNE entering into the market will be a good citizen and is armed 
with a decent ethical standard. Thus, this often leads to delays in legitimation, to continuing suspicion toward the MNE, and to scrutiny of the MNE to a much greater extent than that of local firms [19].

In sum, from the perspective of MNEs, most rules and guidelines are enacted by local authorities, built by the consequence of social standards and often mirrored by the cultural attributes of local economies. This argument indicates that their requirements for legitimacy should plausibly be diverse across national boundaries, and that MNEs particularly need to satisfy a set of institutional domains comprising the three pillars of institutional environments, namely formative, normative and cognitive pillars of institutions.

That is, the lack of information on a particular MNE may force local governments to scrutinize it from a suspicious preconception based on formal regulations and rules (i.e., formative pillar of institutions). The liabilities of foreignness encountered by MNEs are also positively associated with normative institutional pressures in that their inadequate actions against higher unfamiliarity and discriminatory hazards deriving from different local traditions and customs often result in them being targets for attack by host country interest groups [20]. Another aspect of the liability of foreignness is the culturally coerced legitimacy standards (i.e., cognitive pillar of institutions) that some institutional environments differently hold for MNEs compared to local firms. In other words, in many countries, MNEs are anticipated to be more ethical than local firms in supporting local communities, in protecting the environment, and so on [19].

We draw from institutional theory to propose a series of institutional domains based on the three pillars of institutional environments suggested by Scott [21]: the regulatory, the normative, and the cognitive. As briefly discussed above, the regulatory pillar comprises regulatory institutions - that is, formal regulations, rules and laws that govern corporate behavior and pertain in societies to ensure stability and order [21,22]. The regulatory pillar is "distinguished by a prominence given to explicit regulatory processes: rule setting, monitoring, and sanctioning activities. In this view, regulatory processes involve the capacity to establish rules, inspect another's conformity to them, and as needed, manipulate sanctions-rewards or punishments-in an attempt to influence future behavior [21]". The regulatory pillar is commonly created and enacted by governments, authorities, and/or nation-states, which possess official power to form rules and regulations. Firms including MNEs need to conform to the clearly stated requirements of the regulatory system to be legitimate, particularly in the long run, although they do have the ability to influence the regulatory domain through interest intermediation [19]. According to the school of institutional theory (e.g., [19,23]), economists and political scientists often view regulative elements as a vehicle to inspect MNEs' conformity to legitimacy and as an efficient method to prevent MNEs from greasing the wheels of their operations by unethical bribery.

The normative pillar goes beyond regulatory rules to the domain of social values in that in the broad sense, it includes the informal norms, values, standards, roles, conventions, practices, taboos, customs, traditions, and codes of conduct that guide behavior and decisions [21,22]. "Emphasis here is placed on normative rules that introduce a prescriptive, evaluative, and obligatory dimension to social life. Normative systems include both values and norms" [21]. Here, values are abstract ideas about what a society believes to be good, right, and desirable, whereas norms stipulate how things should be done. Thus, normative systems define the appropriate ways to pursue the organizational goals and objectives (e.g., rules specifying how the game is to be played, conceptions of fair business practices) when they are set in the market. In this vein, the normative pillar defines legitimate means to pursue valued ends, which logically indicates that the idea that when in Rome do as the Romans do is clearly wrong and even bribery between Romans is also banned by the normative pillar [24].

The cognitive pillar comprises shared beliefs, categories, identities, schemas, scripts, heuristics, logics of action and mental models [21]. These elements are innately cultural in the sense that social reality is referenced and restructured against external symbolic frameworks, and cognitive in the sense that social reality is understood and built through internalized frames of meaning-making [23]. Thus, firms have to comply with or be consistent with conventional cognitive structures in society to 
be legitimate. In other words, what is legitimate is that which has a 'taken for granted' status [19]. Therefore, it is not difficult to envisage that bribery offered by MNEs in local markets cannot be taken for granted by the cognitive pillar.

Taken together, we propose the following three hypotheses:

Hypotheses 1 (H1): The extent of the regulatory pillar positively influences the inhibition of MNE bribery in local markets.

Hypotheses 2 (H2): The extent of the normative pillar positively influences the inhibition of MNE bribery in local markets.

Hypotheses $3 \mathbf{~ ( H 3 ) : ~ T h e ~ e x t e n t ~ o f ~ t h e ~ c o g n i t i v e ~ p i l l a r ~ p o s i t i v e l y ~ i n f l u e n c e s ~ t h e ~ i n h i b i t i o n ~ o f ~ M N E ~ b r i b e r y ~ i n ~}$ local markets.

\section{Methodology}

\subsection{Data and the Sample}

The data were collected through a questionnaire survey. The items/scales used in the questionnaire were mainly adapted from previous studies, and the survey was carried out from July 2016 to October 2016. For the questionnaire survey, the lists of MNEs in China were obtained with reference to the China Directory of Foreign-invested Firms. Based on the information, 500 foreign-owned subsidiaries located in Beijing, Shanghai, and Shandong were randomly selected. This geographical choice was chosen because these three areas represent the most popular regions attracting inward FDI in China. In the same vein, the Chinese National Bureau of Statistics (NBS) informs that these three regions account for almost half of the total realized inward FDI in China in 2014.

In designing the questionnaire, the problem encountered by authors was that not one of them was Chinese. Thus, after a Korean-language version of the questionnaire was initially prepared, two native Chinese researchers, who were fluent in both Korean and Chinese, translated the Korean-language version of the questionnaire into Chinese. In order to validate the accuracy, the Chinese version was back-translated into Korean by two independent Korean translators who were confident in Chinese. Through active conversations between these Korean and Chinese translators, any conflicts raised by them were discussed until they reached mutual agreement.

Prior to conducting the main survey, we ran a pilot study with two stages. (1) Five academic colleagues, who were studying Chinese language, were asked to review the questionnaire and provide their feedback. (2) A series of in-depth field interviews with senior managers was conducted to gain insight into the focal phenomenon (e.g., institutional pressures in foreign-owned subsidiaries) and to make sure that the content and validity of the measures are acceptable. In this process, we tried to confirm the relevance and completeness of the questionnaire items through the pilot study. The interviews were, in fact, administered by the two Chinese scholars who had contributed to the design of the questionnaire. Based on the experiment, we revised a few questionnaire items to improve their clarity.

We chose the CEO, vice president, senior director, and general managers of the MNE subsidiaries as respondents because we viewed that they should be the best informants on the topic and also be the most suitable representative in each firm. However, in order to enhance the response rate, we offered the option of passing the questionnaire to another senior manager in the case of there being a better informant in the organization who had built network ties with local managers in China. As indicated in many extant studies (e.g., $[25,26]$ ), it is very difficult and challenging to collect primary data from firms in China. As guanxi (i.e., establishing connections, good relationships, and trust with Chinese) is crucial to successfully obtain responses, the survey (i.e., data collection) was administered by the relevant Chinese scholars to support our research. We firmly asked them to specifically guarantee 
the confidentiality of the respondents' responses to ensure that the respondents could participate in the survey without any concerns or worries. In addition, we also promised to provide an executive summary report for all respondents who wished to learn the study findings.

With the support from the aforementioned Chinese scholars, we gathered 126 completed questionnaires out of 500 sent out, representing a response rate of $25.2 \%$. After the exclusion of responses suffering from problems such as missing data, 113 completed questionnaires were used for the final data analysis, giving an effective response rate of $22.6 \%$. With respect to the key firm characteristics, such as firm size and firm age, we checked non-response bias, but no significant differences were found between early and late responses, which indicates a minimal non-response bias.

\subsection{Measures}

The dependent variable, i.e., managerial views on the restraint of corporate bribery practices, was assessed by a three-item scale based on five-point Likert-type responses [27] (see Appendix A for details). Independent variables were three determinants determining the restraints of the corporate bribery practices. Multi-item scales were employed to measure those independent variables. A detailed description and their validity assessment appear in Appendix B. As control variables, we also included firm size, ownership, and industry competition because small and powerless MNE subsidiaries may have a propensity to pay bribes to complement their weakness in the market. Those subsidiaries with less ownership by MNEs accustomed to ethical traditions may be tempted to give a bribe for successful business. Similarly, we think that severe competition may function as a catalyst that induces bribery practices so as not to fall behind in the competitive race. We set firm size as the number of employees, foreign ownership as a continuous variable, and industry competition using a five-point Likert scale ( $1=$ not competitive; $5=$ extremely competitive).

\subsection{Common Method Bias}

We asked the respondents to perceptually measure both dependent and independent variables, which is sometimes feared to introduce common method bias. Thus, in order to confirm the minimum presence of the problem, we ran one-factor analysis in line with the argument presented by Podsakoff, MacKenzie, Lee and Podsakoff [28] stating that "one of the most widely used techniques that has been used by researchers to address the issue of common method bias is what has come to be called Harman's one-factor (or single-factor) test." In following this recommended technique, we entered all predictors, subjectively assessed, into the analysis. We found that the proportion of variance criterion showed three independent dimensions. Managerial views on the restraint of bribery practices and the cognitive pillar had high loadings on the first factor (30.01\%), the regulatory and normative pillars had high loadings on the second factor (29.09\%), and industry competition had a high loading on the third factor $(21.30 \%)$. These results clearly demonstrated the absence of any common method bias.

\section{Results and Discussions}

Table 1 exhibits the descriptive statistics, and particularly the relatively weak correlations between each variable, which indicates that multicollinearity was not a problem. However, to fully confirm the absence of multicollinearity, we calculated the variance inflation factor (VIF). A high value of VIF, previously defined above as 5, suggests the presence of multicollinearity [29], but no prominent evidence of multicollinearity was found from the analysis as none of results exceeded 2 (see Table 2). For reference, more detailed descriptive figure on the sample used in the empirical analysis are provided in Appendix C. 
Table 1. Means, standard deviations, and correlations of variables.

\begin{tabular}{cccccccccc}
\hline Variable & Mean & STD & $\mathbf{1}$ & $\mathbf{2}$ & $\mathbf{3}$ & $\mathbf{4}$ & $\mathbf{5}$ & $\mathbf{6}$ & $\mathbf{7}$ \\
\hline 1. Firm size & 483.70 & 1351.28 & 1.000 & & & & & & \\
2. Firm age & 19.60 & 15.18 & $0.442 * *$ & 1.000 & & & & & \\
3. Foreign ownership & 65.89 & 22.02 & -0.157 & -0.047 & 1.000 & & & & \\
4. Level of competition & 4.42 & 1.31 & 0.021 & -0.055 & -0.082 & 1.000 & & & \\
5. Regulatory pillar & 3.97 & 0.75 & -0.008 & 0.023 & -0.010 & -0.111 & 1.000 & & \\
6. Normative pillar & 3.77 & 0.83 & 0.106 & 0.040 & 0.059 & 0.122 & $0.393^{* *}$ & 1.000 & 1.000 \\
7. Cognitive pillar & 3.83 & 0.84 & 0.084 & -0.092 & -0.183 & 0.118 & $0.280^{* *}$ & $0.433^{* *}$ & $1.0 .524^{* *}$ \\
8. Bribery practices & 4.01 & 0.76 & 0.095 & 0.020 & -0.098 & $0.273^{* *}$ & $0.195^{*}$ & $0.232^{*}$ & -0.50 \\
\hline
\end{tabular}

Notes: $N=113 ;{ }^{* *} p<0.01 ;{ }^{*} p<0.05$.

Ordinary least squares (OLS) regression analysis is commonly utilized in most of extant research attempting to identify the key components influencing a certain phenomenon (e.g., [30-32]). Hair et al. [29] point out that "OLS regression analysis is a statistical technique that can be used to analyze the relationship between a single dependent (criterion) variable and several independent (predictor) variables. The objective of multiple regression analysis is to use the several independent variables whose values are known to predict the single dependent value the researcher wishes to know". Based on previous studies and their explanations, we also used the same technique in order to explore the primary institutional pillars inhibiting corporate bribery practices in China (see Model $1(p<0.001)$. Models 2 and 3, which are associated with spearman rank order correlation analyses, were chosen for reasons given below). The results revealed a cognitive pillar as the most influential institution inhibiting the unethical behavior of MNE subsidiaries in China $(p<0.001)$.

Table 2. Statistical analyses.

\begin{tabular}{ccccc}
\hline Variables & Model 1 $^{\mathbf{a}}$ & Model 2 $^{\mathbf{b}}$ & Model 3 $^{\mathbf{c}}$ & VIF \\
\hline $\begin{array}{c}\text { Control variables } \\
\text { 1. Subsidiary size }\end{array}$ & & & & \\
(Number of employee) & 0.030 & 0.144 & 0.171 & 1.300 \\
2. Subsidiary age & 0.069 & & & 1.279 \\
3. Foreign ownership & 0.017 & -0.143 & -0.187 & 1.059 \\
4. Competition & $0.240^{* * *}$ & $0.404^{* *}$ & $0.436^{* *}$ & 1.065 \\
Institutional pressure & & & & \\
5. Regulatory influence & 0.108 & 0.150 & 0.192 & 1.270 \\
6. Normative influence & -0.057 & 0.114 & 0.139 & 1.427 \\
7. Cognitive influence & $0.489^{* * *}$ & $0.439^{* *}$ & $0.324^{*}$ & 1.323 \\
Adjusted R $R^{2}$ & 0.284 & & & \\
F & $7.052^{* * *}$ & & & \\
\hline
\end{tabular}

Notes: ${ }^{\mathrm{a}}$ regression analysis; $N=113 ;{ }^{* * *} p<0.001 ;{ }^{* *} p<0.01{ }^{*} p<0.05 .{ }^{\mathrm{b}}$ Spearman rank order correlations for old subsidiaries; $N=47 ;{ }^{* *} p<0.01 ;{ }^{*} p<0.05$. ${ }^{\mathrm{c}}$ Spearman rank order correlations for young subsidiaries; $N=66$; ${ }^{* *} p<0.01 ; * p<0.05$.

It is common wisdom that China is a representative country for Confucianism as a religious and philosophical tradition dating back 2500 years in China, which subsequently permeated throughout East Asia. The main goal of Confucianism in ancient China was to restore social and political harmony by reviving the moral attributes in the society. The most important philosophical tradition of Confucianism is perhaps that a moral inclination is given to people by Heaven, that human nature is inherently good, and thus that moral virtue strongly regulates human life in China. These philosophical beliefs emphasize that people have to be ethical and moral, or otherwise they will be punished by Heaven. Therefore, such philosophical beliefs as Confucianism are rampant in China, and the cognitive institution resides deeply in the people's sub-consciousness (see [33]). In addition, we view that the cognitive convention rooted in Confucianism (i.e., cognitive pillar) does not only play a pivotal role in inhibiting local firms' bribery practices but also in pushing MNE subsidiaries to be good citizens in the research context. 
In addition, no one may deny that MNEs are prone to encounter cultural newness and subsequent discriminatory hazards [34]. Compared to local firms, key stakeholders (e.g., customers etc.) in local markets often use stereotypes and idiosyncratic standards in judging cultural aliens (i.e., MNEs), which could result in delaying in legitimation, in maintaining suspicion toward the MNE, and in supervising the MNEs to a much greater extent than that of local firms [19]. These stakeholders in many host countries anticipate MNEs to carry out more benevolence than local firms so that they build their reputation and goodwill, support local societies, and contribute to social welfare, and so on. This suggests that operation difficulties based on cultural cognitive elements function as a catalyst enhancing the MNE's strategic motivation to lessen foul business practices in the host country.

In order to thoroughly check the result, we further divided the sample into two groups: old versus young MNE subsidiaries. However, this extra effort jeopardized the study because the sample size for each subsidiary type was too small to run an OLS regression analysis (i.e., sample sizes for old and young subsidiaries are 47 and 66, respectively. For reference, the overall sample is divided into two groups based on the number of years in operation up to the time of data collection by using cluster analysis.). With the following explanation, Park [34] points out that the use of Spearman rank correlation coefficient can be a viable alternative to solve this problem: "one or both variables may be ordinal; or if both variables are interval, the normality requirement may not be satisfied. In such cases, we measure and test to determine whether a relationship exists by employing a nonparametric technique, the spearman rank correlation coefficient". By adopting his advice, we used the Spearman rank order correlation analysis to overcome the small sample size problem and further found, importantly, that the results (i.e., a decisive institutional pillar inhibiting bribery practices in China) were exactly the same as the outcomes from the overall sample, regardless of the subsidiary age (we also ran further analyses based on subsidiary size and industry competitions and found some interesting statistical outcomes. Results and subsequent brief discussions are provided in Appendix D). This clearly demonstrates that the shared beliefs and social identity stemming from Confucianism function as a vehicle to retard the greasing of wheels in China [35].

\section{Conclusions}

The key motivation of this study is to examine what inhibits the bribery practices of MNE subsidiaries directed at local managers in China. Based on institutional theory and survey data, we used two different statistical techniques (i.e., both regression and spearman rank correlation analyses) to demonstrate a decisive institutional pillar that contributes to the inhibition. The results of our analyses clearly show that a cognitive pillar is a crucial determinant, regardless of the subsidiary age in China. This study makes several essential contributions to the theory and research on MNE bribery in general and on China in particular.

Prior empirics have theoretically emphasized the central role that inward FDI triggers in host country economic development, while also enhancing the productivity of local organizations in the host country [36]. While some previous studies adopted the institutional perspective as an overarching theoretical lens for their examinations into inward FDI in the host economy, to the best of our knowledge, no one has tried to link the theory and bribery practices especially in the East Asian emerging markets [37]. The importance of the cognitive pillar as demonstrated in this study confirms that Confucian ideas disseminated throughout China significantly promote ethical business behaviors and good citizenships in China, which effectively retards bribery practices by MNE subsidiaries in alien environments. Furthermore, the findings reveal that the shared beliefs comprising the cognitive pillar can meaningfully facilitate sustainable development in China.

Our findings also present several useful implications for MNE managers and policy makers. Our study suggests that when MNEs enter emerging economies they are often tempted to give bribes to local suppliers and business partners in order to grease the wheels and complement their weaknesses. Nevertheless, foreign firm managers are faced with the quandary of whether or not to behave as Romans when they are in Rome. Our findings connecting bribery and institutional environments 
suggest that Chinese countrywide recognition is based on the cognitive pillar and that it is deeply rooted in Confucianism. This clearly indicates that when MNE subsidiaries try to be Romans, the real Romans (i.e., possibly Chinese consumers and non-governmental organizations), as key stakeholders armed with moral emotion, will oversee and supervise MNE behaviors. Thus, although a few Chinese businessmen run their businesses unethically, it is not a good idea for MNE managers to imitate the local behavior in this regard. In addition, policy makers should note that institutional quality in China is significantly determined by the people's cognitive structure, at least in China, and therefore it is worthwhile that those policy makers attempt to strengthen Confucian concepts, value and thinking in order to enhance institutional quality and an ethical business atmosphere.

Although this study provides important theoretical contributions and useful implications for both MNE managers and policy makers in China, we acknowledge the study experiences some limitations. First, this study was undertaken only in the Chinese context, meaning that the study results may differ from those in other countries. Therefore, our research framework needs to be applied in other geographical areas, such as African economies and/or the conventional triad (i.e., the United States, Europe and Japan). Second, as we used only statistical data collected through questionnaire survey, we cannot be sure whether our findings will be supported by qualitative evidence. This shortcoming necessitates the use of a triangulation method, which investigates the same topic variously with quantitative information and qualitative interviews. Third, we drew a comparison between old versus young subsidiaries. However, this will also extend our understanding on the issue when other studies compare other groups, such as (1) Greenfield vs. Brownfield investments, (2) manufacturing vs. service sectors, and (3) majority vs. minority foreign ownerships. Fourth, we did not investigate possible interactions among institutions and bribery practices because we only observed a cause and effect relationship. Based on this limitation, examinations of interactions between variables, for instance, through AMOS, can be another research avenue. Finally, we agree that we may enrich the statistical results in the case where we include the industrial sector of the MNEs, the country of origin of the MNE subsidiary, and city-level control variables for the population, gross domestic product, and agglomeration of economic activity in the analyses. With respect to the first two factors, so many respondents left those questions as a missing value, whereas city-level control variables were not embodied in the questionnaire. We concede these factors as critical limitations of this study.

Author Contributions: Based on mutual co-operations, the paper was written by K.-S.O. and Y.-S.R. The second author (i.e., Y.-S.R.) contributed to designing the research model and interpreting the statistical outcomes, whereas the residual work was done by the first author (i.e., K.-S.O.). All authors have read and approved the final manuscript.

Funding: This research received no external funding.

Conflicts of Interest: The authors declare no conflict of interest.

\section{Appendix A}

The measurements of the dependent variable (partly adopted from [27]) (Cronbach's $\alpha: 0.765$ )

1 Our company has established a set of transparent, comprehensive, and stringent codes of conduct with the goal of resisting bribery in managerial positions.

2 Throughout the company, every manager and employee has strictly implemented the above codes of conduct.

3 Our company has established an ethics compliance department or division to specifically handle the improvement, training, and enforcement of the above codes of conduct.

\section{Appendix B}

The measurements of independent variables.

1 Regulatory influence (adapted from [38]): (1) The local government and authorities have stricter regulations to prohibit bribery. (2) The local government and authorities have effective regulations 
to encourage firms to improve ethical business. (3) There are complete laws and regulations to ensure fair competition. (Cronbach's $\alpha$ : 0.727).

2 Normative influence (created by this study): (1) The society strongly prohibits bribery as one of the main forms of corruption. (2) The society considers social justice to be the most important value. (3) We often define rectitude as social obligation, which is naturally supposed to be fulfilled as a member of society. (Cronbach's $\alpha$ : 0.789).

3 Cognitive influence (created by this study): (1) Moral practices are highly emphasized in our culture. (2) Bribe-offering has long been regarded as a cultural taboo in the business custom. (3) In short, integrity is integral to our cultural identity in our life. (Cronbach's $\alpha: 0.774)$.

\section{Appendix C}

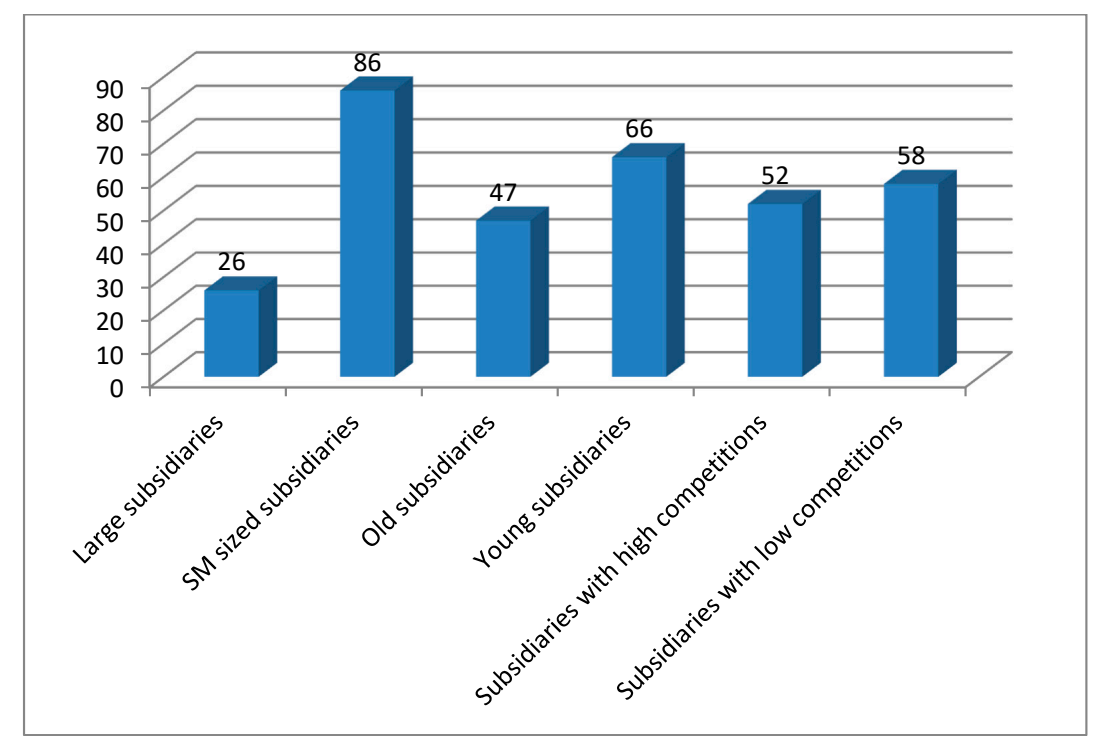

Figure A1. Descriptive graph and sampling (Notes: subsidiary size is classified into two groups based on explanations given by [4] (SM means small and medium); the overall sample on subsidiary age is also divided into two groups based on the number of years in operation up to the time of data collection by using cluster analysis; subsidiaries with high versus low competitions were grouped by using cluster analysis; With respect to size and industry competitions, one and three respondents did not report and thus they remain as missing values, respectively.).

\section{Appendix D}

Table A1. Statistical analyses.

\begin{tabular}{ccccc}
\hline Variables & Model 4 $^{\mathbf{a}}$ & Model 5 $^{\mathbf{b}}$ & Model 6 $^{\mathbf{c}}$ & Model 7 $^{\mathbf{d}}$ \\
\hline $\begin{array}{c}\text { Control variables } \\
\text { 1. Subsidiary size }\end{array}$ & & & & \\
(Number of employee) & & & $0.315^{*}$ & -0.115 \\
2. Subsidiary age & 0.129 & 0.010 & 0.175 & -0.023 \\
3. Foreign ownership & $-0.423^{*}$ & 0.048 & 0.059 & -0.196 \\
4. Competition & $0.619^{* *}$ & 0.097 & & \\
Institutional pressure & & & & \\
5. Regulatory influence & 0.081 & $0.343^{* *}$ & $0.406^{* *}$ & 0.180 \\
6. Normative influence & -0.058 & $0.228^{*}$ & $0.287^{*}$ & 0.103 \\
7. Cognitive influence & 0.335 & $0.479^{* *}$ & $0.417^{* *}$ & $0.429^{* *}$ \\
\hline
\end{tabular}

Notes: ${ }^{a}$ Spearman rank order correlations for large subsidiaries; $N=26 ;{ }^{* *} p<0.01 ;{ }^{*} p<0.05 .{ }^{\mathrm{b}}$ Spearman rank order correlations for small and medium sized subsidiaries; $N=86 ;{ }^{* *} p<0.01 ; * p<0.05$. ${ }^{\mathrm{c}}$ Spearman rank order correlations for subsidiaries with high competitions; $N=52 ; * * p<0.01 ; * p<0.05$. ${ }^{\mathrm{d}}$ Spearman rank order correlations for subsidiaries with low competitions; $N=58 ;{ }^{* *} p<0.01 ;{ }^{*} p<0.05$. 
We found some interesting results through the additional analyses. According to the statistical outcomes, subsidiaries with foreign majority ownership have a propensity to pay briberies in local market (the dependent variable is managerial views on the restraint of corporate bribery practices, and foreign ownership is negatively significant). MNEs entering into foreign markets are not philanthropists but they are eager to make profits through the investments. Our results clearly inform us that as expected, they pay considerable attention to profit maximization and generally ignore ethical management abroad, though their corporate headquarters are accustomed to a well-organized institutional environment and know how they should behave. Our findings also indicate that due to their organizational bargaining power, large firms are seldom afraid of institutional coercion. In contrast, our experiments reveal that unlike the large firms, all three institutional pressures play a pivotal role in inhibiting small subsidiaries' bribery practices in China. Meanwhile, similarly to the results from main analyses (i.e., Models 1-3), our extra test points out that the level of competition affects bribery practices to some extent, and thus we grouped the sample into subsidiaries with high versus low competition and examined the differences between those groups. We can infer from the findings that institutional influences work especially under severe competitions.

\section{References}

1. Oh, K.-S.; Anchor, J. Factors affecting reverse knowledge transfer from subsidiaries to multinational companies: Focusing on the transference of local market information. Can. J. Adm. Sci. 2017, 34, 329-342. [CrossRef]

2. Park, B.I.; Cave, A.H. Corporate social responsibility in international joint ventures: Empirical examinations in South Korea. Int. Bus. Rev. 2018, 27, 1213-1228. [CrossRef]

3. Xiao, S.S.; Park, B.I. Bring institutions into FDI spillover research: Exploring the impact of ownership restructuring and institutional development in emerging economies. Int. Bus. Rev. 2017, 27, 289-308. [CrossRef]

4. Park, B.I; Gauri, P.N. Determinants influencing CSR practices in small and medium sized MNE subsidiaries: A stakeholder perspective. J. World Bus. 2015, 50, 192-204. [CrossRef]

5. Cuerovo-Cazurra, A. Better the devil you don't know: Types of corruption and FDI in transition economies. J. Int. Manag. 2008, 14, 12-27. [CrossRef]

6. Evan, T.; Bolotov, I. The weak relation between foreign direct investment and corruption: A theoretical and econometric study. Prague Econ. Papers 2014, 4, 474-492. [CrossRef]

7. Birhanu, A.G.; Gambardella, A.; Valentini, G. Bribery and investment: Firm-level evidence from Africa and Latin America. Strateg. Manag. J. 2016, 37, 1865-1877. [CrossRef]

8. Galang, R.M.N. Government efficiency and international technology adoption: The spread of electronic ticketing among airlines. J. Int. Bus. Stud. 2012, 43, 631-654. [CrossRef]

9. Xia, H.; Tan, Q.; Bai, J. Corruption and technological innovation in private small-medium scale companies: Does female top management play a role? Sustainability 2018, 10, 2252. [CrossRef]

10. Xia, X.; Qi, G.; Zhu, K.X. Corruption and new product innovation: Examining firms' ethical dilemmas in transition economies. J. Bus. Ethics 2018, 1-9. [CrossRef]

11. Suchman, M.C. Managing legitimacy: Strategy and institutional approaches. Acad. Manag. Rev. 1995, 20, 571-610. [CrossRef]

12. DiMaggio, P.; Powell, W.W. The iron cage revisited: Institutional isomorphism and collective rationality in organizational fields. Am. Sociol. Rev. 1983, 42, 147-160. [CrossRef]

13. Valentino, A.; Schmitt, J.; Koch, B.; Nell, P.C. Leaving home: An institutional perspective on intermediary HQ relocations. J. World Bus. 2019, 54, 273-284. [CrossRef]

14. Shukla, P.; Cantwell, J. Migrants and multinational firms: The role of institutional affinity and connectedness in FDI. J. World Bus. 2018, 53, 835-849. [CrossRef]

15. Li, J.; Xia, J.; Shapiro, D.; Lin, Z. Institutional compatibility and the internationalization of Chinese SOEs: The moderating role of home subnational institutions. J. World Bus. 2018, 53, 641-652. [CrossRef]

16. Hillman, A.; Wan, W.P. The determinants of MNE subsidiaries' political strategies: Evidence of institutional duality. Sustainability 2005, 36, 322-340. [CrossRef] 
17. Hymer, S.H. The International Operations of National Firms: A Study of Direct Foreign Investment; MIT Press: Cambridge, MA, USA, 1976.

18. North, D.C. Institutions. J. Econ. Pers. 1991, 5, 97-112. [CrossRef]

19. Kostova, T.; Zaheer, S. Organizational legitimacy under conditions of complexity: The case of the multinational enterprise. Acad. Manag. Rev. 1999, 24, 64-81. [CrossRef]

20. Eden, L.; Miller, S.R. Distance matters: Liabilities of foreignness, institutional distance and ownership strategy. In Advances in International Management; Hitt, M., Cheng, J., Eds.; Elsevier: Amsterdam, The Netherlands, 2004; Volume 16, pp. 187-221.

21. Scott, W.R. Institutions and Organizations; Sage: Thousand Oaks, CA, USA, 2001.

22. North, D.C. Understading the Process of Economic Change; Princeton University Press: Princeton, NJ, USA, 2005.

23. Orr, R.J.; Scott, W.R. Institutional exceptions on global projects: A process model. J. Int. Bus. Stud. 2008, 39, 562-588. [CrossRef]

24. Wu, Z; Salomon, R. Does imitation reduce the liability of foreignness? Linking distance, isomorphism, and performance. Strateg. Manag. J. 2016, 37, 2441-2462. [CrossRef]

25. Brouthers, L.E.; $\mathrm{Xu}, \mathrm{K}$. Product stereotypes, strategy and performance satisfaction: The case of Chinese exporters. J. Int. Bus. Stud. 2002, 33, 657-677. [CrossRef]

26. Peng, M.W.; Luo, Y. Managerial ties and firm performance in a transition economy: The nature of a micro-macro link. Acad. Manag. J. 2000, 43, 486-501.

27. Luo, Y. Political behavior, social responsibility, and perceived corruption: A structuration perspective. J. Int. Bus. Stud. 2006, 37, 747-766. [CrossRef]

28. Podsakoff, P.M.; MacKenzie, S.B.; Lee, J.Y.; Podsakoff, N.P. Common method biases in behavioral research: A critical review of the literature and recommended remedies. J. Appl. Psychol. 2003, 88, 879-903. [CrossRef] [PubMed]

29. Hair, J.F., Jr.; Anderson, R.E.; Tatham, R.L.; Black, W.C. Multivariate Data Analysis; Prentice-Hall: Upper Saddle River, NJ, USA, 1998.

30. Kim, J.; Oh, K.-S. Introduction of shareholder-friendly behaviors after governance reform in Korean firms: Is it a proactive response? Emerg. Mark. Financ. Trade 2015, 51, 351-363. [CrossRef]

31. Lane, P.J.; Salk, J.E.; Lyles, M.A. Absorptive capacity, learning, and performance in international joint ventures. Strateg. Manag. J. 2001, 22, 1139-1161. [CrossRef]

32. Park, B.I. Knowledge transfer capacity of multinational enterprises and technology acquisition in international joint ventures. Int. Bus. Rev. 2011, 20, 75-87. [CrossRef]

33. Adler, J.A. Confucianism in China Today. 2011. Available online: https://www2.kenyon.edu/Depts/Religion/ Fac/Adler/Writings/Confucianism\%20Today.pdf (accessed on 30 May 2019).

34. Park, B.I. What changes the rules of the game in wholly owned subsidiaries? Determinants of knowledge acquisition from parent firms. Int. Bus. Rev. 2012, 21, 547-557. [CrossRef]

35. Park, J.H.; Park, H.Y.; Lee, H.Y. The effect of social ties between outside and inside directors on the association between corporate social responsibility and firm value. Sustainability 2018, 10, 3840. [CrossRef]

36. Sara, A.; Pietro, M.P.C. Inward greenfield FDI and patterns of job polarization. Sustainability 2018, 10, 1219.

37. Valentina, D.R.; Angela, R. Entrepreneurial activity in the EU: An empirical evaluation of its determinants. Sustainability 2017, 9, 1679.

38. Qu, R. Effects of government regulations, market orientation and ownership structure on corporate social responsibility in China: An empirical study. Int. J. Manag. 2007, 24, 582-591.

(C) 2019 by the authors. Licensee MDPI, Basel, Switzerland. This article is an open access article distributed under the terms and conditions of the Creative Commons Attribution (CC BY) license (http://creativecommons.org/licenses/by/4.0/). 